\title{
Methanol, Formaldehyde, and Sodium Formate Exposure in Rat and Mouse Conceptuses: A Potential Role of the Visceral Yolk Sac in Embryotoxicity
}

\author{
Jason M. Hansen, ${ }^{2}$ Kristi M. Contreras, ${ }^{1}$ and Craig Harris ${ }^{1 *}$ \\ ${ }^{1}$ Toxicology Program, Department of Environmental Health Sciences, School of Public Health, University of Michigan, \\ Ann Arbor, Michigan \\ ${ }^{2}$ Department of Biochemistry, School of Medicine, Emory University, Atlanta, Georgia
}

Received 9 August 2004; Accepted 19 October 2004

\begin{abstract}
BACKGROUND: Methanol $\left(\mathrm{CH}_{3} \mathrm{OH}\right)$ is believed to be teratogenic based on rodent studies. The mouse is more sensitive than the rat, but mechanisms of toxicity and identification of teratogenic metabolites are uncertain. METHODS: Rat and mouse whole embryo cultures are used to distinguish toxicity of $\mathrm{CH}_{3} \mathrm{OH}$ and its metabolites, formaldehyde $(\mathrm{HCHO})$ and formate $(\mathrm{HCOONa})$, which are produced following transit through the visceral yolk sac (VYS), via addition to culture medium, or by direct embryonic exposure through microinjection into the amnion. RESULTS: Embryonic viability, increased dysmorphogenesis, and decreased growth parameters were altered in a dose-dependent fashion for each compound. Mouse embryos were more sensitive than rat, as indicated by significant decreases in viability at comparable, lower concentrations. HCHO produced dysmorphogenesis and caused embryolethality at nearly 1000 -fold lower concentrations $(0.004 \mathrm{mg} / \mathrm{ml})$ than seen with either $\mathrm{CH}_{3} \mathrm{OH}$ or $\mathrm{HCOONa}$. All agents produced incomplete axial rotation and delayed neural tube closure in mice, but only $\mathrm{CH}_{3} \mathrm{OH}$ elicited similar effects in the rat. Increased growth retardation, blood pooling in the head and VYS, enlarged pericardium, accumulation of necrotic matter in the amnion, and hypoplastic prosencephalon were observed in both species with all compounds. Microinjection of compounds into the amnion produced higher mortality in mouse and rat, compared to equimolar amounts added to the culture medium. $\mathrm{CH}_{3} \mathrm{OH}$ did not prevent neural tube closure in the rat when microinjected. CONCLUSIONS: $\mathrm{HCHO}$ is the most embryotoxic $\mathrm{CH}_{3} \mathrm{OH}$ metabolite and elicits the entire spectrum of lesions produced by $\mathrm{CH}_{3} \mathrm{OH}$. The VYS serves a general protective role against toxicity and inherent differences in the embryonic metabolism of $\mathrm{CH}_{3} \mathrm{OH}$ may determine species sensitivity. Birth Defects Research (Part A) 73:72-82, 2005.
\end{abstract}

(c) 2004 Wiley-Liss, Inc.

Key words: embryotoxicity; methanol; formaldehyde; formate; rat; mouse; visceral yolk sac

\section{INTRODUCTION}

Methanol $\left(\mathrm{CH}_{3} \mathrm{OH}\right)$ is a widely used industrial solvent that has also been suggested for use as an alternative automotive fuel, thus increasing the risk for human exposure. Current human exposure to $\mathrm{CH}_{3} \mathrm{OH}$ primarily occurs via the ingestion of common alcoholic beverages and fruit juices, application of cosmetics, deicing fluids, and varnishes (von Burg, 1994; Lanigan, 2001; Davis et al, 2002). Because $\mathrm{CH}_{3} \mathrm{OH}$ is found relatively ubiquitously in our environment, it becomes increasingly important to understand its toxic effects, including those on the developing embryo (Clary, 2003).

Many studies describe the deleterious effects of $\mathrm{CH}_{3} \mathrm{OH}$ during development through implementation of the whole embryo culture system and demonstration of nonlethal teratogenicity at concentrations of upwards of $8.75 \mathrm{mg} / \mathrm{ml}$ in the rat (Andrews et al., 1998). $\mathrm{CH}_{3} \mathrm{OH}$ concentrations of $4 \mathrm{mg} / \mathrm{ml}$ had no effect on developing rat embryos, but $\mathrm{CH}_{3} \mathrm{OH}$ concentrations higher than $2 \mathrm{mg} / \mathrm{ml}$ began to

Grant sponsor: U.S. Environmental Protection Agency; Grant number: Cr821964; Grant sponsor: National Institutes of Health; Grant number: ES07062.

${ }^{*}$ Correspondence to: Craig Harris, Ph.D., Toxicology Program, Department of Environmental Health Sciences, University of Michigan, 1420 Washington Heights, Ann Arbor, MI 48109-2029. E-mail: charris@umich.edu

Published online 1 December 2004 in Wiley InterScience (www.interscience. wiley.com).

DOI: $10.1002 /$ bdra.20094 
have harmful effects on mouse embryos, as indicated by decreased developmental scores and morphological parameters. Furthermore, $\mathrm{CH}_{3} \mathrm{OH}$ concentrations of 12 $\mathrm{mg} / \mathrm{ml}$ showed some embryolethality in the rat, but using $\mathrm{CH}_{3} \mathrm{OH}$ concentrations of $8 \mathrm{mg} / \mathrm{ml}$ produced $80 \%$ embryolethality in mice (Andrews et al., 1993), suggesting that the mouse embryo is more sensitive to $\mathrm{CH}_{3} \mathrm{OH}$ exposure in vitro.

Methanol metabolism in adults occurs primarily in the liver, but the early embryonic/fetal liver does not have similar detoxification functions and may rely on other tissues for subsequent $\mathrm{CH}_{3} \mathrm{OH}$ metabolism (Zorzano and Herrera, 1989; Dawidek-Pietryka et al, 1998). Conversion of $\mathrm{CH}_{3} \mathrm{OH}$ to formaldehyde $(\mathrm{HCHO})$ in humans is catalyzed primarily by alcohol dehydrogenase 1 (ADH1) (Ma and Harris, 1988; Harris et al, 2003). Alternative pathways of metabolism include catalase-mediated reactions, yielding $\mathrm{HCHO}$ and hydrogen peroxide (Cederbaum and Qureshi, 1982). HCHO was previously discounted as an ultimate embryotoxin because of its high reactivity and the supposition that it would not diffuse between cells, would covalently react immediately with adjacent macromolecules, or would be rapidly and completely converted to nontoxic metabolites. HCHO is converted to formic acid $(\mathrm{HCOOH})$ by the nicotinamide adenine dinucleotide (NAD) dependent alcohol dehydrogenase 3 (ADH3). This reaction uses glutathione (GSH) as a cofactor and yields S-formylglutathione prior to thiol cleavage and $\mathrm{HCOOH}$ formation. Formic acid is converted to water and carbon dioxide via catalase. Rodents are known to remove formic acid at much higher rates than do humans, and the acidosis caused by formic acid accumulation is believed to be an important contributor to several manifestations of methanol toxicity (Burbacher et al., 1999; Lanigan, 2001). It is not clear whether formic acid accumulation in the conceptus is sufficient to account for observed embryotoxicity.

While previous experiments have described interesting dissimilarities between mouse and rat responses to $\mathrm{CH}_{3} \mathrm{OH}$ exposure, they may not accurately represent the effects of $\mathrm{CH}_{3} \mathrm{OH}$ specifically on the embryo. Unlike humans, rodent embryos are surrounded by the visceral yolk sac (VYS) during early organogenesis and throughout gestation. Besides the nutritional and early hematopoietic functions, the VYS is also believed to play additional physical and metabolic protective roles during development. The relative contributions of GSH in the embryo and VYS have been described to contribute to $\mathrm{CH}_{3} \mathrm{OH}$ embryotoxicity in vitro (Harris et al. 2004). Rat VYS GSH concentrations in early organogenesis-staged conceptuses are approximately 30\% greater than those in the embryo proper (Harris, 1993). Following GSH depletion, the VYS functions to replenish GSH via de novo synthesis (Harris, 1993). Only after VYS GSH repletion is completed does embryonic GSH begin to recover. Many other enzymes involved in detoxification and embryo protection are found to have higher specific activities in the VYS, suggesting that the VYS is the first line of defense against xenobiotics, oxidants, and toxicants (Harris, 1993; Choe et al., 2001; Harris et al., 2003). For example, ADH1, formaldehyde dehydrogenase (ADH3), and catalase activities in the 6-10 somite stage early organogenesis-staged rat and mouse conceptuses are higher in the VYS when compared to the embryo proper (Harris et al., 2003).
Unlike rodent models, human development appears not to rely on the protective effects of the VYS. Human embryonic VYSs are anatomically different from the rodent VYS and do not encompass the entire embryo throughout gestation. Therefore, human embryos are more likely to be directly exposed to toxicants and may be more prone to teratogenesis due to the lack of physical and metabolic protection offered by the rodent VYS. A more accurate extrapolation of rodent studies to human $\mathrm{CH}_{3} \mathrm{OH}$ exposure may be accomplished through the evaluation of direct exposure of the embryo proper rather than $\mathrm{CH}_{3} \mathrm{OH}$ exposure to the entire conceptus, as previously performed in whole embryo culture (Andrews et al., 1993, 1995, 1998; Abbott et al., 1995; Bolon et al., 1994).

In this study, we compare and evaluate the effects of $\mathrm{CH}_{3} \mathrm{OH}$ and $\mathrm{CH}_{3} \mathrm{OH}$-related metabolites, $\mathrm{HCHO}$ and $\mathrm{HCOONa}$, on the embryo, introduced by addition to the culture medium and by microinjection directly into the amnionic cavity, effectively bypassing the VYS. Due to the previously observed differences between mouse and rat responses to $\mathrm{CH}_{3} \mathrm{OH}$ in whole embryo culture, the following studies were performed in CD-1 mouse and SpragueDawley rat conceptuses to provide a cross-species comparison.

\section{MATERIALS AND METHODS Animals}

Time-mated primigravida CD-1 mice and Sprague-Dawley rats were obtained from the Reproductive Sciences Small Animal Facility, University of Michigan (Ann Arbor, $\mathrm{MI})$. The morning of a positive vaginal smear was designated day 0 of pregnancy (GD 0). On GD 8 in the mouse and GD 10 in the rat, conceptuses were removed from the uteri and prepared for culture.

\section{Whole Embryo Culture}

Rat and mouse whole embryo culture was performed as described by Fantel et al. (1979) and Harris et al. (1987). Each rat conceptus (8-10 somites; GD 10) was prepared for culture and placed in bottles (1 conceptus /ml of media) with warm media consisting of 33\% (vol/vol) heat-inactivated pregnant rat serum and $66 \%$ Hank's balanced salt solution (HBSS, pH 7.4). Culture bottles containing conceptuses and media were placed in a rotating drum (BTC Engineering, Cambridge, UK) under constant gassing conditions of $20 \% \mathrm{O}_{2} / 5 \% \mathrm{CO}_{2} / 75 \%$ $\mathrm{N}_{2}$ (vol/vol/vol) and maintained at $37^{\circ} \mathrm{C}$ for a $20-\mathrm{hr}$ period. Atmospheric conditions were changed to $95 \%$ $\mathrm{O}_{2} / 5 \% \mathrm{CO}_{2}$ (vol/vol) during the final $4 \mathrm{hr}$ on the following day (GD 11) to meet the metabolic requirements of the developing conceptus.

Each mouse conceptus (GD 8) was prepared in a similar manner as described for the rat, with slight modifications. Mouse conceptuses were cultured in $66 \%$ heat-inactivated serum and 33\% Tyrode's solution for $24 \mathrm{hr}$. Gas and culture conditions are identical to those outlined for the rat whole embryo culture. Names of chemicals and the amounts added directly to the culture medium are listed in Tables 1, 2, and 3 .

At the end of culture, the VYS was carefully removed from the rest of the embryo, placed in appropriate buffers, snap-frozen in liquid nitrogen, and then placed in a freezer at $-70^{\circ} \mathrm{C}$ until prepared for DNA and protein quantification. The embryo was evaluated morphologically to deter- 
Table 1

Developmental Parameters Following $\mathrm{CH}_{3} \mathrm{OH}$ Exposure by Direct Addition to the Culture Medium or Microinjection Into the Amnionic Space*

\begin{tabular}{|c|c|c|c|c|c|c|c|}
\hline \multicolumn{8}{|c|}{ Direct addition to the culture medium } \\
\hline Control & $\begin{array}{c}\text { Dose } \\
(\mathrm{mg} / \mathrm{ml})\end{array}$ & $\begin{array}{c}\% \text { viable } \\
(n)\end{array}$ & $\begin{array}{l}\text { \% normal } \\
\text { rotation } \\
(n)\end{array}$ & $\begin{array}{l}\text { CR length } \\
\mathrm{mm} \pm \text { SEM } \\
(n)\end{array}$ & $\begin{array}{c}\text { \% neural } \\
\text { tube closure } \\
(n)\end{array}$ & $\begin{array}{c}\text { Embryo/VYS } \\
\text { protein } \\
( \pm \text { SEM }) \\
\end{array}$ & $\begin{array}{c}\text { Embryo/VYS } \\
\text { DNA } \\
( \pm S E M) \\
\end{array}$ \\
\hline \multicolumn{2}{|l|}{ Mouse } & $\begin{array}{r}94 \\
(137)\end{array}$ & $\begin{array}{r}93 \\
(132)\end{array}$ & $\begin{array}{c}3.0 \pm 0.3 \\
(112)\end{array}$ & $\begin{array}{l}92 \\
(131)\end{array}$ & $\begin{array}{c}251.4 / 197.1 \\
( \pm 1.1 / 0.8)\end{array}$ & $\begin{array}{c}17.3 / 12.7 \\
( \pm 0.1 / 0.2)\end{array}$ \\
\hline \multirow[t]{5}{*}{$\mathrm{CH}_{3} \mathrm{OH}$} & 4.0 & $\begin{array}{l}100 \\
(6)\end{array}$ & $\begin{array}{l}50^{\mathrm{a}} \\
(6)\end{array}$ & $2.81 \pm 0.2$ & $\begin{array}{l}67 \\
(6)\end{array}$ & $\begin{array}{c}251.9 / 191.1 \\
( \pm 2.3 / 2.2)\end{array}$ & $\begin{array}{r}22.7 / 5.9^{\mathrm{a}} \\
( \pm 0.4 / 0.1)\end{array}$ \\
\hline & 8.0 & $\begin{array}{l}71^{\mathrm{a}} \\
(21)\end{array}$ & $\begin{array}{r}87 \\
(15)\end{array}$ & $2.7 \underset{(13)}{ \pm} 0.2$ & $\begin{array}{l}67^{\mathrm{a}} \\
(15)\end{array}$ & $\begin{array}{c}216.1^{\mathrm{a}} / 214.1 \\
( \pm 8.1 / 5.0)\end{array}$ & $\begin{array}{l}10.3^{\mathrm{a}} / 5.1^{\mathrm{a}} \\
( \pm 0.9 / 0.1)\end{array}$ \\
\hline & 10.0 & $30^{\mathrm{a}}$ & $0^{\mathrm{a}}$ & NA & $0^{\mathrm{a}}$ & $95.8^{\mathrm{a}} / 163.7^{\mathrm{a}}$ & $4.9^{\mathrm{a}} / 4.7^{\mathrm{a}}$ \\
\hline & & (10) & (3) & & (3) & $( \pm 8.8 / 10.4)$ & $( \pm 0.9 / 0.2)$ \\
\hline & 12.0 & $\begin{array}{r}0^{\mathrm{a}} \\
(16)\end{array}$ & NA & NA & NA & NA & NA \\
\hline \multicolumn{2}{|l|}{ Rat } & $\begin{array}{l}100 \\
(52)\end{array}$ & $\begin{array}{r}92 \\
(52)\end{array}$ & $3.21 \underset{(48)}{ \pm} 0.03$ & $\begin{array}{l}100.0 \\
(52)\end{array}$ & $\begin{array}{c}288.9 / 189.6 \\
( \pm 7.51 / 5.05)\end{array}$ & $\begin{array}{c}19.9 / 8.2 \\
( \pm 0.7 / 0.3)\end{array}$ \\
\hline \multirow[t]{6}{*}{$\mathrm{CH}_{3} \mathrm{OH}$} & 8.0 & 100 & $40^{\mathrm{a}}$ & $3.05 \pm 0.1$ & 100.0 & $200.9^{\mathrm{a}} / 178.2$ & $20.1 / 10.0$ \\
\hline & \multirow{2}{*}{12.0} & $\begin{array}{l}(5) \\
100\end{array}$ & $\begin{aligned}(5) & \\
0^{\mathrm{a}} & \end{aligned}$ & $\begin{array}{l}(4) \\
\text { NA }\end{array}$ & $\begin{array}{l}(5) \\
50.0^{\mathrm{a}}\end{array}$ & $\begin{array}{l}( \pm 15.8 / 10.3) \\
84.3^{\mathrm{a}} / 128.5^{\mathrm{a}}\end{array}$ & $\begin{array}{c}( \pm 3.1 / 0.6) \\
9.2^{\mathrm{a}} / 5.3^{\mathrm{a}}\end{array}$ \\
\hline & & (5) & $(4)$ & & $(4)$ & $( \pm 4.9 / 3.7)$ & $( \pm 0.8 / 0.4)$ \\
\hline & \multirow[t]{2}{*}{16.0} & $50^{\mathrm{a}}$ & $0^{\mathrm{a}}$ & NA & $40.0^{\mathrm{a}}$ & $55.0^{\mathrm{a}} / 108.7^{\mathrm{a}}$ & $4.2^{\mathrm{a}} / 6.5^{\mathrm{a}}$ \\
\hline & & (10) & (5) & & (5) & $( \pm 2.2 / 4.8)$ & $( \pm 0.3 / 0.7)$ \\
\hline & 20.0 & $\begin{array}{l}0^{\mathrm{a}} \\
(5)\end{array}$ & NA & NA & NA & NA & NA \\
\hline \multicolumn{8}{|c|}{ Microinjection } \\
\hline Control & $\begin{array}{l}\text { Dose } \\
(\mu \mathrm{g})\end{array}$ & $\begin{array}{c}\% \text { viable } \\
(n)\end{array}$ & $\begin{array}{l}\% \text { normal } \\
\text { rotation } \\
(n)\end{array}$ & $\begin{array}{l}\text { CR length } \\
\text { mm } \underset{ \pm}{ \pm} \\
\text { SEM }(n)\end{array}$ & $\begin{array}{c}\% \text { neural } \\
\text { tube closure } \\
(n)\end{array}$ & $\begin{array}{c}\text { Embryo/ } \\
\text { VYS protein } \\
( \pm \text { SEM })\end{array}$ & $\begin{array}{c}\text { Embryo/VYS } \\
\text { DNA } \\
( \pm \text { SEM })\end{array}$ \\
\hline \multirow{2}{*}{\multicolumn{2}{|c|}{ Mouse }} & 92 & 94 & $3.0 \pm 0.3$ & 91 & 251.4/197.1 & $17.3 / 12.7$ \\
\hline & & (72) & $(67)$ & $(51)$ & (67) & $( \pm 1.1 / 0.8)$ & $( \pm 0.1 / 0.2)$ \\
\hline \multirow{8}{*}{$\mathrm{CH}_{3} \mathrm{OH}$} & \multirow[t]{2}{*}{$1-45$} & 83 & $53^{\mathrm{a}}$ & $3.0 \pm 0.2$ & $67^{a}$ & $194.6^{\mathrm{a}} / 181.5$ & $20.8 / 7.2^{a}$ \\
\hline & & (18) & (15) & $(8)$ & (15) & $( \pm 5.9 / 4.9)$ & $( \pm 0.9 / 0.2)$ \\
\hline & \multirow[t]{2}{*}{$46-89$} & $25^{a}$ & $0^{\mathrm{a}}$ & NA & $25^{\mathrm{a}}$ & $253.4 / 222.4$ & $29.8^{\mathrm{a}} / 8.9$ \\
\hline & & (16) & (4) & & (4) & $( \pm 11.6 / 8.1)$ & $( \pm 2.3 / 0.9)$ \\
\hline & \multirow[t]{2}{*}{ 90-134 } & $62^{a}$ & $0^{a}$ & NA & $0^{\mathrm{a}}$ & $205.3^{a} / 178.7$ & $16.3 / 6.3^{a}$ \\
\hline & & (8) & (5) & & (5) & $( \pm 8.43 / 8.2)$ & $( \pm 0.9 / 0.2)$ \\
\hline & \multirow[t]{2}{*}{$135-178$} & $20^{\mathrm{a}}$ & $0^{\mathrm{a}}$ & NA & $0^{\mathrm{a}}$ & $142.7^{\mathrm{a}} / 156.1^{\mathrm{a}}$ & $9.4^{\mathrm{a}} / 4.1^{\mathrm{a}}$ \\
\hline & & (5) & (1) & & (1) & $( \pm 3.70 / 10.4)$ & $( \pm 0.2 / 0.6)$ \\
\hline \multirow[t]{2}{*}{ Rat } & & 100 & 100 & $3.2 \pm 0.3$ & 100 & $286.4 / 180.5$ & $25.7 / 9.3$ \\
\hline & & (15) & (15) & (15) & (15) & $( \pm 14.3 / 8.4)$ & $( \pm 1.4 / 0.4)$ \\
\hline \multirow[t]{8}{*}{$\mathrm{CH}_{3} \mathrm{OH}$} & \multirow[t]{2}{*}{$1-45$} & 100 & 88 & $3.5 \pm 0.2$ & 88 & $263.7 / 139.2$ & $26.0 / 7.0$ \\
\hline & & (34) & (25) & (22) & (34) & $( \pm 6.3 / 6.0)$ & $( \pm 0.4 / 0.2)$ \\
\hline & \multirow[t]{2}{*}{$46-89$} & $60^{a}$ & $50^{a}$ & $3.4 \pm 0.3$ & 100 & $236.4 / 140.0$ & $23.8 / 8.0$ \\
\hline & & (30) & (18) & (9) & (18) & $( \pm 18.2 / 11.1)$ & $( \pm 2.5 / 0.7)$ \\
\hline & \multirow{2}{*}{ 90-134 } & 88 & $25^{a}$ & $3.4 \pm 0.3$ & 95 & $240.3 / 159.6$ & $25.3 / 7.8$ \\
\hline & & (24) & (24) & (6) & (24) & $( \pm 17.3 / 5.9)$ & $( \pm 2.3 / 0.5)$ \\
\hline & \multirow[t]{2}{*}{$135-178$} & $79^{\mathrm{a}}$ & $26^{a}$ & $3.3 \pm 0.4$ & 100 & $255.3 / 164.7$ & $23.9 / 7.5$ \\
\hline & & (19) & (19) & (5) & (19) & $( \pm 16.9 / 5.5)$ & $( \pm 2.0 / 0.8)$ \\
\hline
\end{tabular}

*Conceptuses were cultured for $24 \mathrm{hr}$ beginning on gestational day 8 in the CD-1 mouse and gestational day 10 in the Sprague-Dawley rat according to the protocols described in Materials and Methods.

${ }^{\mathrm{a} D e n o t e s}$ a statistically significant difference from control $(p<0.05)$.

mine growth and developmental abnormalities, namely viability, flexure and rotation, crown-rump length, and neuropore closure. Somite counts did not show any changes across treatment groups and are not included in the tables. Embryos that were not viable were not evaluated for any subsequent growth and morphological parameters. Similarly, embryos that failed to undergo normal flexure and rotation were not evaluated for crown-rump length.

\section{Microinjection}

Procedures for microinjection of GD 10 conceptuses were performed essentially as described by Stark et al. (1990) (Fig. 1). Blank borosilicate glass capillaries (outer diameter [OD] $1.0 \mathrm{~mm}$; inner diameter [ID] $0.78 \mathrm{~mm}$; Sutter Instrument, Novato, CA) were pulled to extended tapers on a Model P-87 Flaming/Brown Micropipette Puller and fractured under a stereo dissecting microscope to a $15-20 \mu \mathrm{m}$ tip diameter. 
Table 2

Developmental Parameters Following HCHO Exposure by Direct Addition to the Culture Medium or Microinjection Into the Amnionic Space*

\begin{tabular}{|c|c|c|c|c|c|c|c|}
\hline \multicolumn{8}{|c|}{ Direct addition to the culture medium } \\
\hline Control & $\begin{array}{r}\text { Dose } \\
(\mathrm{mg} / \mathrm{ml}) \\
\end{array}$ & $\begin{array}{c}\% \text { viable } \\
(n)\end{array}$ & $\begin{array}{l}\% \text { normal } \\
\text { rotation } \\
(n)\end{array}$ & $\begin{array}{l}\text { CR length } \\
\text { mm } \underset{ \pm}{ \pm} \\
\text { SEM }(n)\end{array}$ & $\begin{array}{c}\% \text { neural } \\
\text { tube closure } \\
(n)\end{array}$ & $\begin{array}{c}\text { Embryo/ } \\
\text { VYS protein } \\
( \pm \text { SEM })\end{array}$ & $\begin{array}{c}\text { Embryo/VYS } \\
\text { DNA } \\
( \pm \text { SEM }) \\
\end{array}$ \\
\hline Mouse & & $\begin{array}{l}94 \\
(137)\end{array}$ & $\begin{array}{c}93 \\
(132)\end{array}$ & $\begin{array}{c}3.0 \pm 0.3 \\
(112)\end{array}$ & $\begin{array}{c}92 \\
(131)\end{array}$ & $\begin{array}{c}251.4 / 197.1 \\
( \pm 1.1 / 0.8)\end{array}$ & $\begin{array}{r}17.3 / 12.7 \\
( \pm 0.1 / 0.2)\end{array}$ \\
\hline \multirow[t]{6}{*}{$\mathrm{HCHO}$} & 0.001 & $\begin{array}{l}91 \\
(56)\end{array}$ & $\begin{array}{r}63 \\
(51)\end{array}$ & $3.1 \pm 0.2$ & $\begin{array}{l}71^{\mathrm{a}} \\
(51)\end{array}$ & $\begin{array}{c}251.9 / 191.1 \\
( \pm 2.3 / 2.2)\end{array}$ & $\begin{array}{r}22.7 / 5.9^{\mathrm{a}} \\
( \pm 0.4 / 0.1)\end{array}$ \\
\hline & 0.003 & 92 & $54^{\mathrm{a}}$ & $2.9 \pm 0.0$ & $15^{\mathrm{a}}$ & $216.1^{\mathrm{a}} / 214.1$ & $10.3^{\mathrm{a}} / 5.1^{\mathrm{a}}$ \\
\hline & & $(14)$ & $(13)$ & (7) & $(13)$ & $( \pm 8.1 / 5.0)$ & $( \pm 0.9 / 0.1)$ \\
\hline & 0.004 & $4^{\mathrm{a}}$ & 0 & NA & 100 & $95.8^{\mathrm{a}} / 163.7^{\mathrm{a}}$ & $4.9^{\mathrm{a}} / 4.7^{\mathrm{a}}$ \\
\hline & & (28) & (1) & & (1) & $( \pm 0.0 / 0.0)$ & $( \pm 0.0 / 0.0)$ \\
\hline & 0.006 & $\begin{array}{l}0^{\mathrm{a}} \\
(42)\end{array}$ & NA & NA & NA & NA & NA \\
\hline \multicolumn{2}{|l|}{ Rat } & $\begin{array}{l}100.0 \\
(52)\end{array}$ & $\begin{array}{r}92 \\
(52)\end{array}$ & $3.21 \underset{(48)}{ \pm} 0.3$ & $\begin{array}{c}100.0 \\
(52)\end{array}$ & $\begin{array}{c}288.9 / 189.6 \\
( \pm 7.5 / 5.0)\end{array}$ & $\begin{array}{c}19.9 / 8.2 \\
( \pm 0.72 / 0.33)\end{array}$ \\
\hline \multirow[t]{7}{*}{$\mathrm{HCHO}$} & 0.001 & 100 & $\begin{array}{r}91 \\
(11)\end{array}$ & $\begin{array}{c}3.20 \pm 0.0 \\
(11)\end{array}$ & 100.0 & $322.3 / 202.2$ & $\begin{array}{c}22.1 / 8.1 \\
( \pm 1.1 / 0.2)\end{array}$ \\
\hline & 0.003 & 100 & $40^{\mathrm{a}}$ & $3.20 \pm 0.1$ & 100.0 & $261.2 / 175.2$ & $15.1^{\mathrm{a}} / 5.5^{\mathrm{a}}$ \\
\hline & 0.004 & 100 & $20^{\mathrm{a}}$ & $3.10 \pm 0.7$ & 100.0 & $259.3^{\mathrm{a}} / 164.9^{\mathrm{a}}$ & $15.9^{\mathrm{a}} / 5.8$ \\
\hline & & $(225)$ & (25) & $(8)$ & $(25)$ & $( \pm 7.6 / 4.5)$ & $( \pm 0.8 / 0.2)$ \\
\hline & 0.006 & $22^{\mathrm{a}}$ & $0^{\mathrm{a}}$ & NA & 100 & $200.1^{\mathrm{a}} / 144.4^{\mathrm{a}}$ & $8.7^{\mathrm{a}} / 3.4^{\mathrm{a}}$ \\
\hline & & (22) & (15) & & (5) & $( \pm 9.8 / 5.7)$ & $( \pm 0.8 / 0.4)$ \\
\hline & 0.008 & $\begin{array}{c}0^{\mathrm{a}} \\
(13) \\
\end{array}$ & NÁ & NA & NA & NA & NA \\
\hline \multicolumn{8}{|c|}{ Microinjection } \\
\hline Control & $\begin{array}{l}\text { Dose } \\
(\mu \mathrm{g})\end{array}$ & $\begin{array}{c}\% \text { viable } \\
(n)\end{array}$ & $\begin{array}{c}\text { \% normal } \\
\text { rotation } \\
(n)\end{array}$ & $\begin{array}{l}\text { CR length } \\
\mathrm{mm} \pm \mathrm{SEM} \\
(n)\end{array}$ & $\begin{array}{l}\text { \% neural } \\
\text { tube closure } \\
(n)\end{array}$ & $\begin{array}{l}\text { Embryo/ } \\
\text { VYS protein } \\
( \pm \text { SEM })\end{array}$ & $\begin{array}{c}\text { Embryo/VYS } \\
\text { DNA } \\
( \pm \text { SEM }) \\
\end{array}$ \\
\hline Mouse & & $\begin{array}{r}92 \\
(72)\end{array}$ & $\begin{array}{r}94 \\
(67)\end{array}$ & $3.0 \pm 0.3$ & $\begin{array}{r}91 \\
(67)\end{array}$ & $\begin{array}{c}251.4 / 197.1 \\
( \pm 1.1 / 0.8)\end{array}$ & $\begin{array}{r}17.3 / 12.7 \\
( \pm 0.1 / 0.2)\end{array}$ \\
\hline \multirow[t]{6}{*}{$\mathrm{HCHO}$} & $0.003-0.5$ & $\begin{array}{r}62^{a} \\
(35)\end{array}$ & $\begin{array}{l}63^{\mathrm{a}} \\
(22)\end{array}$ & $3.1 \pm 0.3$ & $\begin{array}{l}71^{a} \\
(35)\end{array}$ & $\begin{array}{r}251.9 / 191.1 \\
( \pm 2.3 / 2.2)\end{array}$ & $\begin{array}{c}22.7 / 5.9^{a} \\
( \pm 0.4 / 0.1)\end{array}$ \\
\hline & $0.501-1.0$ & $32^{\mathrm{a}}$ & $33^{\mathrm{a}}$ & $2.9 \pm 0.0$ & $14^{\mathrm{a}}$ & $216.1^{\mathrm{a}} / 214.1$ & $10.3^{\mathrm{a}} / 5.1^{\mathrm{a}}$ \\
\hline & & $(28)$ & (9) & (7) & $(28)$ & $( \pm 8.1 / 5.0)$ & $( \pm 0.9 / 0.1)$ \\
\hline & $1.01-1.5$ & $7^{a}$ & 0 & NA & 100 & $95.8^{a} / 163.7^{a}$ & $4.9^{\mathrm{a}} / 4.7^{\mathrm{a}}$ \\
\hline & & (14) & (1) & & (1) & $( \pm 0.0 / 0.0)$ & $( \pm 0.9 / 0.2)$ \\
\hline & $1.51-2.0$ & $\begin{array}{c}0^{\mathrm{a}} \\
(9)\end{array}$ & NA & NA & NA & NA & NA \\
\hline \multirow[t]{2}{*}{ Rat } & & 100 & 100 & $3.2 \pm 0.3$ & 100 & $286.4 / 180.5$ & $25.7 / 9.3$ \\
\hline & & (15) & (15) & (15) & (15) & $( \pm 14.3 / 8.4)$ & $( \pm 1.4 / 0.4)$ \\
\hline \multirow[t]{8}{*}{$\mathrm{HCHO}$} & $0.003-0.5$ & 100 & 100 & $3.5 \pm 0.2$ & 100 & $302.8 / 217.2$ & $26.9 / 9.7$ \\
\hline & & $(42)$ & (42) & $(42)$ & $(42)$ & $( \pm 2.7 / 2.2)$ & $( \pm 1.5 / 0.5)$ \\
\hline & $0.501-1.0$ & 100 & 100 & $3.4 \pm 0.3$ & 100 & $331.9 / 196.2$ & $28.0 / 9.1$ \\
\hline & & (6) & (6) & (6) & (6) & $( \pm 3.7 / 3.6)$ & $( \pm 1.9 / 0.6)$ \\
\hline & $1.01-1.5$ & $42^{\mathrm{a}}$ & $60^{a}$ & $3.3 \pm 0.4$ & 80 & $315.9 / 189.9$ & $30.7 / 9.0$ \\
\hline & & (12) & (5) & (3) & (5) & $( \pm 8.2 / 6.5)$ & $( \pm 3.9 / 0.5)$ \\
\hline & $1.51-2.0$ & $27^{\mathrm{a}}$ & 0 & NA & 100 & $238.2^{\mathrm{a}} / 171.3$ & $27.8 / 10.9$ \\
\hline & & (11) & (3) & & (3) & $( \pm 7.7 / 17.4)$ & $( \pm 2.8 / 0.4)$ \\
\hline
\end{tabular}

*Conceptuses were cultured for $24 \mathrm{hr}$ beginning on gestational day 8 in the CD-1 mouse and gestational day 10 in the Sprague-Dawley rat according to the protocols described in Materials and Methods.

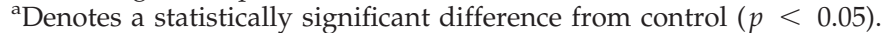

Fractured tip diameters were verified using a stage micrometer. Micropipettes were individually calibrated for the volume of fluid delivered per timed-pulse, using $\left[{ }^{14} \mathrm{C}\right]$-sucrose of known specific activity diluted in deionized water. Test articles, $\mathrm{CH}_{3} \mathrm{OH}, \mathrm{HCHO}$, and $\mathrm{HCOONa}$, were diluted in deionized water and microinjected directly into the amniotic space by supporting the conceptus with forceps and gently inserting the calibrated micropipette using a hand-held stylus, through the VYS and into the amnion. A timed-pulse was delivered at an injection pressure of 10 psi using a Nikon Model PLI-188 pressure injection system. Quantities of test article were calculated from known starting concentrations and calibration volumes/pulse for each individual pipette. Controls were sham-injected with equivalent volumes of deionized water and cultured according to the usual protocols. 
Table 3

Developmental Parameters Following HCOONa Exposure by Direct Addition to the Culture Medium or Microinjection Into the Amnionic Space*

\begin{tabular}{|c|c|c|c|c|c|c|c|}
\hline \multicolumn{8}{|c|}{ Direct addition to the culture medium } \\
\hline Control & $\begin{array}{l}\text { Concentration } \\
(\mathrm{mg} / \mathrm{ml})\end{array}$ & $\begin{array}{c}\% \text { viable } \\
(n)\end{array}$ & $\begin{array}{l}\text { \% normal } \\
\text { rotation } \\
(n)\end{array}$ & $\begin{array}{l}\text { CR length } \\
\mathrm{mm} \pm \underset{(n)}{ \pm} \text { SEM }\end{array}$ & $\begin{array}{l}\% \text { neural tube } \\
\text { closure }(n)\end{array}$ & $\begin{array}{l}\text { Embryo/VYS } \\
\text { protein ( }( \pm \text { SEM) }\end{array}$ & $\begin{array}{c}\text { Embryo/ } \\
\text { VYS DNA } \\
( \pm \text { SEM })\end{array}$ \\
\hline \multicolumn{2}{|l|}{ Mouse } & $\begin{array}{c}94 \\
(137)\end{array}$ & $\begin{array}{c}93 \\
(132)\end{array}$ & $\begin{array}{c}3.0 \pm 0.3 \\
(112)\end{array}$ & $\begin{array}{c}92 \\
(131)\end{array}$ & $\begin{array}{c}251.4 / 197.1 \\
( \pm 1.1 / 0.8)\end{array}$ & $\begin{array}{l}17.3 / 12.7 \\
( \pm 0.1 / 0.2)\end{array}$ \\
\hline \multirow[t]{4}{*}{ HCOONa } & 0.5 & $\begin{array}{r}94 \\
(18)\end{array}$ & $\begin{array}{l}76^{\mathrm{a}} \\
(17)\end{array}$ & $2.9 \pm 0.2$ & $\begin{array}{l}88 \\
(17)\end{array}$ & $\begin{array}{c}247.9 / 187.4 \\
( \pm 4.8 / 4.2)\end{array}$ & $\begin{array}{l}17.7 / 6.25^{\mathrm{a}} \\
( \pm 0.8 / 0.2)\end{array}$ \\
\hline & 1.0 & $\begin{array}{l}100 \\
(17)\end{array}$ & $\begin{array}{r}94 \\
(17)\end{array}$ & $2.9 \pm 0.3$ & $\begin{array}{l}88 \\
(17)\end{array}$ & $\begin{array}{c}258.2 / 191.4 \\
( \pm 2.5 / 1.6)\end{array}$ & $\begin{array}{l}15.9 / 5.0^{\mathrm{a}} \\
( \pm 0.3 / 0.1)\end{array}$ \\
\hline & 2.0 & $\begin{array}{r}90 \\
(17)\end{array}$ & $\begin{array}{l}70^{\mathrm{a}} \\
(17)\end{array}$ & $3.1 \pm 0.3$ & $\begin{array}{l}60^{\mathrm{a}} \\
(17)\end{array}$ & $\begin{array}{c}272.5 / 179.4 \\
( \pm 7.3 / 6.0)\end{array}$ & $\begin{array}{l}15.2 / 4.8^{\mathrm{a}} \\
( \pm 0.9 / 0.2)\end{array}$ \\
\hline & 4.0 & 93 & $54^{\mathrm{a}}$ & $2.8 \pm 0.2$ & 85 & $219.5^{\mathrm{a}} / 155.4^{\mathrm{a}}$ & $12.6 / 4.1^{\mathrm{a}}$ \\
\hline Rat & & $\begin{array}{l}100 \\
(52)\end{array}$ & $\begin{array}{r}92 \\
(52)\end{array}$ & $3.2 \pm 0.03$ & $\begin{array}{c}100.0 \\
(52)\end{array}$ & $\begin{array}{c}288.9 / 189.6 \\
( \pm 7.51 / 5.05)\end{array}$ & $\begin{array}{c}19.9 / 8.2 \\
( \pm 0.72 / 0.33)\end{array}$ \\
\hline \multirow[t]{5}{*}{ HCOONa } & 0.5 & $\begin{array}{r}97 \\
(29)\end{array}$ & $\begin{array}{r}93 \\
(28)\end{array}$ & $3.4 \underset{(28)}{ \pm} 0.0$ & $\begin{array}{l}100 \\
(28)\end{array}$ & $\begin{array}{c}305.8 / 192.2 \\
( \pm 16.6 / 10.4)\end{array}$ & $\begin{array}{l}24.7 / 9.7 \\
( \pm 2.3 / 0.5)\end{array}$ \\
\hline & 1.0 & $\begin{array}{r}87 \\
(15)\end{array}$ & $\begin{array}{r}85 \\
(13)\end{array}$ & $3.3 \underset{(11)}{ \pm} 0.3$ & $\begin{array}{l}100 \\
(13)\end{array}$ & $\begin{array}{l}309.9 / 180.7 \\
( \pm 19.2 / 7.8)\end{array}$ & $\begin{array}{l}26.7 / 9.5 \\
( \pm 2.1 / 0.6)\end{array}$ \\
\hline & 2.0 & $\begin{array}{l}60^{\mathrm{a}} \\
(5)\end{array}$ & $\begin{array}{l}100 \\
(3)\end{array}$ & $3.2 \pm 0.3$ & $\begin{array}{c}100 \\
(3)\end{array}$ & $\begin{array}{c}235.8^{\mathrm{a}} / 180.3 \\
( \pm 12.7 / 15.4)\end{array}$ & $\begin{array}{l}23.5 / 8.2 \\
( \pm 2.0 / 1.6)\end{array}$ \\
\hline & 4.0 & $\begin{array}{l}47^{\mathrm{a}} \\
(19)\end{array}$ & $\begin{array}{l}78^{\mathrm{a}} \\
(9)\end{array}$ & $3.2 \pm 0.1$ & $\begin{array}{r}100 \\
(9)\end{array}$ & $\begin{array}{c}268.9 / 163.5 \\
( \pm 27.5 / 12.3)\end{array}$ & $\begin{array}{l}29.2 / 10.1 \\
( \pm 4.3 / 0.6)\end{array}$ \\
\hline & 8.0 & $\begin{array}{r}0^{\mathrm{a}} \\
(5)\end{array}$ & NA & NA & NA & NA & NA \\
\hline
\end{tabular}

\begin{tabular}{|c|c|c|c|c|c|c|c|}
\hline \multicolumn{8}{|c|}{ Microinjection } \\
\hline Control & $\begin{array}{c}\text { Concentration } \\
(\mu \mathrm{g})\end{array}$ & $\begin{array}{c}\% \text { viable } \\
(n)\end{array}$ & $\begin{array}{l}\text { \% normal } \\
\text { rotation } \\
(n)\end{array}$ & $\begin{array}{l}\text { CR length } \\
\mathrm{mm} \pm \text { SEM } \\
(n)\end{array}$ & $\begin{array}{c}\text { \% neural } \\
\text { tube closure } \\
(n)\end{array}$ & $\begin{array}{c}\text { Embryo/ } \\
\text { VYS protein } \\
( \pm \text { SEM })\end{array}$ & $\begin{array}{c}\text { Embryo/VYS } \\
\text { DNA } \\
( \pm \text { SEM })\end{array}$ \\
\hline \multicolumn{2}{|l|}{ Mouse } & $\begin{array}{l}92 \\
(72)\end{array}$ & $\begin{array}{r}94 \\
(67)\end{array}$ & $3.0 \pm 0.3$ & $\begin{array}{l}91 \\
(67)\end{array}$ & $\begin{array}{c}251.4 / 197.1 \\
( \pm 1.1 / 0.8)\end{array}$ & $\begin{array}{l}17.3 / 12.7 \\
( \pm 0.1 / 0.2)\end{array}$ \\
\hline \multirow[t]{4}{*}{ HCOONa } & $0.03-0.5$ & $\begin{array}{c}100 \\
(11)\end{array}$ & $\begin{array}{l}73^{\mathrm{a}} \\
(11)\end{array}$ & $2.9 \pm 0.2$ & $\begin{array}{l}91 \\
(11)\end{array}$ & $\begin{array}{c}247.9 / 187.4 \\
( \pm 4.8 / 4.2)\end{array}$ & $\begin{array}{l}17.7 / 6.25^{\mathrm{a}} \\
( \pm 0.8 / 0.2)\end{array}$ \\
\hline & $0.51-1.0$ & $\begin{array}{l}82 \\
(17)\end{array}$ & $\begin{array}{l}21^{\mathrm{a}} \\
(14)\end{array}$ & $2.9 \pm 0.3$ & $\begin{array}{l}79 \\
(14)\end{array}$ & $\begin{array}{c}258.2 / 191.4 \\
( \pm 2.5 / 1.6)\end{array}$ & $\begin{array}{l}15.9 / 5.0^{\mathrm{a}} \\
( \pm 0.3 / 0.1)\end{array}$ \\
\hline & $1.01-1.5$ & $\begin{array}{l}65^{\mathrm{a}} \\
(17)\end{array}$ & $\begin{array}{l}27^{\mathrm{a}} \\
(11)\end{array}$ & $2.9 \pm 0.3$ & $55^{\mathrm{a}}$ & $\begin{array}{c}272.5 / 179.4 \\
( \pm 7.3 / 6.0)\end{array}$ & $\begin{array}{l}15.2 / 4.8^{\mathrm{a}} \\
( \pm 0.9 / 0.2)\end{array}$ \\
\hline & $1.51-4.0$ & $\begin{array}{l}0^{\mathrm{a}} \\
(7)\end{array}$ & NA & NA & NA & NA & NA \\
\hline Rat & & $\begin{array}{l}100 \\
(15)\end{array}$ & $\begin{array}{l}100 \\
(15)\end{array}$ & $3.2 \pm 0.3$ & $\begin{array}{l}100 \\
(15)\end{array}$ & $\begin{array}{l}286.4 / 180.5 \\
( \pm 14.3 / 8.4)\end{array}$ & $\begin{array}{l}25.7 / 9.3 \\
( \pm 1.4 / 0.4)\end{array}$ \\
\hline \multirow[t]{4}{*}{ HCOONa } & $0.03-0.5$ & $\begin{array}{l}95 \\
(20)\end{array}$ & $\begin{array}{r}89 \\
(19)\end{array}$ & $3.1 \pm 0.02$ & $\begin{array}{c}100 \\
(19)\end{array}$ & $\begin{array}{l}300.2 / 201.1 \\
( \pm 11.2 / 9.8)\end{array}$ & $\begin{array}{l}20.1 / 9.3 \\
( \pm 0.7 / 0.4)\end{array}$ \\
\hline & $0.51-1.0$ & $\begin{array}{l}90 \\
(10)\end{array}$ & $\begin{array}{l}11^{\mathrm{a}} \\
(9)\end{array}$ & $2.8 \pm 0.03$ & $\begin{array}{c}100.0 \\
(9)\end{array}$ & $\begin{array}{c}209.4^{\mathrm{a}} / 181.7 \\
(6.8 / 10.2)\end{array}$ & $\begin{array}{l}9.7^{\mathrm{a}} / 5.2^{\mathrm{a}} \\
( \pm 0.7 / 0.3)\end{array}$ \\
\hline & $\begin{array}{c}1.01-1.5 \\
\text { (9) }\end{array}$ & $\begin{array}{l}78 \\
(7)\end{array}$ & $0^{a}$ & $\begin{array}{l}\text { NA } \\
(4)\end{array}$ & $\begin{array}{c}25.0^{\mathrm{a}} \\
( \pm 6.1 / 7.9)\end{array}$ & $\begin{array}{c}134.6^{\mathrm{a}} / 142.4^{\mathrm{a}} \\
( \pm 0.3 / 0.2)\end{array}$ & $4.9^{\mathrm{a}} / 3.4^{\mathrm{a}}$ \\
\hline & $1.51-4.0$ & $\begin{array}{l}0.0^{\mathrm{a}} \\
(10)\end{array}$ & NA & NA & NA & NA & NA \\
\hline
\end{tabular}

${ }^{*}$ Conceptuses were cultured for 24 hr beginning on gestational day 8 in the CD-1 mouse and gestational day 10 in the Sprague-Dawley rat according to the protocols described in Materials and Methods.

${ }^{a}$ Denotes a statistically significant difference from control $(p<0.05)$.

\section{DNA and Protein Quantification}

DNA content for both the embryo proper and the VYS was determined using a method as outlined by Labarca and Paigen (1980). Embryonic and VYS protein content was determined using the method of Bradford (1976) and modified for a microplate reader as outlined by Stark et al. (1987).

\section{Statistics}

Significant differences between species for control values were determined by performing a Student's $t$-test. Differences within the treatments of similar species were determined by a two-way ANOVA; $p$ values that were at or below 0.05 were considered significantly different. 

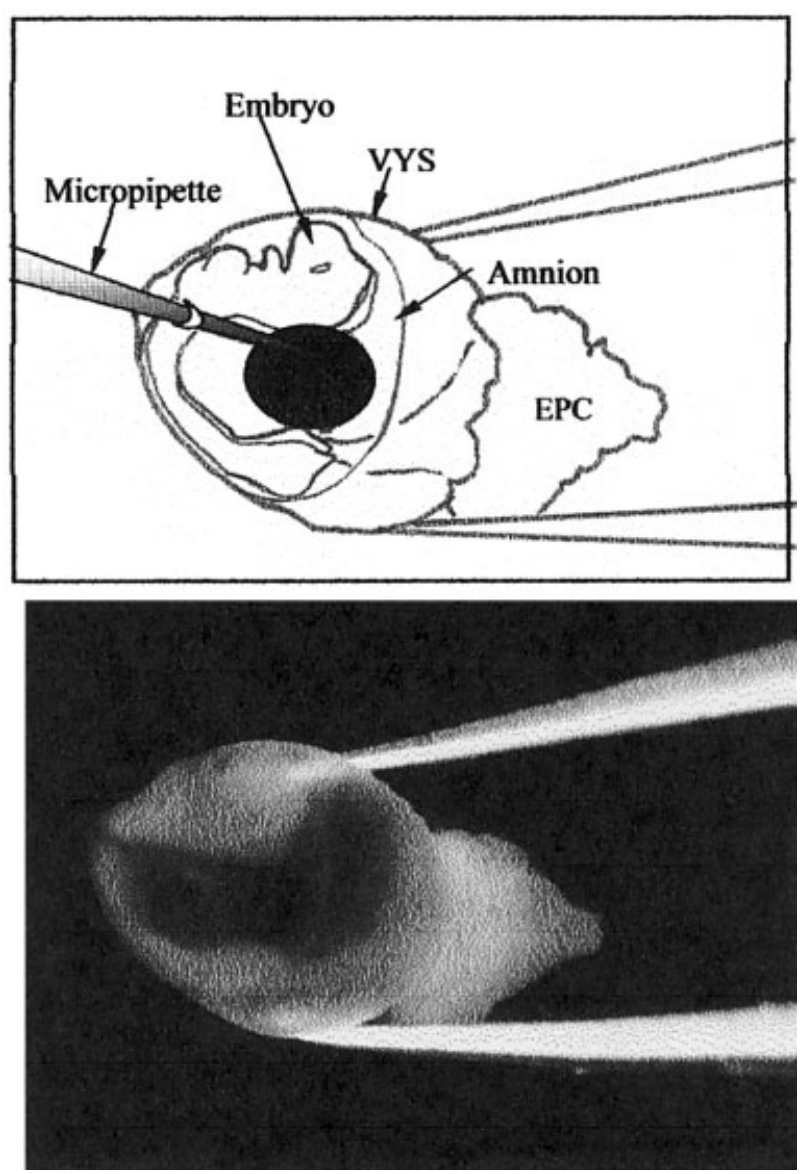

Figure 1. Microinjection of 8-12 somite rat and mouse conceptuses. A pulled, fractured and calibrated borosilicate glass micropipette is inserted through the VYS and amnion into the space between the dorsally flexed embryos. This figure depicts the microinjection of trypan blue dye (for visualization) using a single timed pulse at a pressure of $10 \mathrm{psi}$. Controls are sham-injected and show the rapid closure of the VYS around the injection site after the micropipette is removed.

\section{RESULTS}

\section{Morphology Assessments}

Rat and mouse conceptuses exposed to $\mathrm{CH}_{3} \mathrm{OH}, \mathrm{HCHO}$, and HCOONa all showed some degree of disruption of the vitelline vasculature of the VYS, with abnormal blood pooling and the formation of clear fluid-filled blisters (Fig. 2A2 and B2). Prominent dysmorphogenesis in both species included incomplete axial rotation and failure of the anterior neuropore to close (Fig. 2C2 and D2). These events are normally completed between the 12-15 somite stages in rats and mice, during a period in which growth in whole embryo culture is optimal. Many exposed conceptuses exhibited abnormal blood pooling in the head and lateral body wall regions, especially surrounding the mesencephalon between the optic cup and otic vesicle (Fig. 2D2, E1, and E2). The latter also appeared to be associated with hemorrhage. Other dysmorphogenic effects observed in both mouse and rat conceptuses were enlarged, clear, fluid-filled pericardium (Fig. 2C2 and F) and necrotic debris in the amnionic space (Fig. 2H). All affected conceptuses showed some alterations in VYS appearance and embryos were significantly growth-retarded (Fig. 2G and I).

\section{Methanol: Direct Addition to the Culture Medium}

The direct addition of $\mathrm{CH}_{3} \mathrm{OH}$ and its primary metabolites, $\mathrm{HCHO}$ and $\mathrm{HCOONa}$, to the media in whole embryo culture each produced loss of embryo viability, overall growth, and increased malformation in a dose-dependent manner.

Mouse conceptuses first encountered significant losses of viability at $\mathrm{CH}_{3} \mathrm{OH}$ doses of $8 \mathrm{mg} / \mathrm{ml}$, added directly to the culture medium, as indicated in Table 1. Significant decreases in axial rotation and increased incidence of neural tube defects were evident at doses of $4 \mathrm{mg} / \mathrm{ml}$ (statistically significant at $8 \mathrm{mg} / \mathrm{ml}$ ). Protein and DNA content of embryos and VYS were used to assess of overall growth. Protein content was significantly reduced at $8 \mathrm{mg} / \mathrm{ml}$, with embryo and VYS levels being further reduced at $10 \mathrm{mg} / \mathrm{ml}$ $\mathrm{CH}_{3} \mathrm{OH}$. Visceral yolk sac DNA was significantly decreased beginning at $4 \mathrm{mg} / \mathrm{ml}$, followed by reductions in embryo and VYS when $\mathrm{CH}_{3} \mathrm{OH}$ was at $8 \mathrm{mg} / \mathrm{ml}$.

Rat conceptuses did not show significant a loss of viability until $\mathrm{CH}_{3} \mathrm{OH}$ concentrations exceeded $16 \mathrm{mg} /$ $\mathrm{ml}$, suggesting that, by this criterion, the rat is more resistant than the mouse. Abnormal axial rotation was significant above $8 \mathrm{mg} / \mathrm{ml}$, but no increase in incidence of incomplete neural tube closure was seen until concentrations reached $12 \mathrm{mg} / \mathrm{ml}$. Embryonic protein content decreased in inverse proportion to the dose of $\mathrm{CH}_{3} \mathrm{OH}$ administered. Dramatic losses of embryonic protein were not proportional to the more attenuated losses of VYS protein. Significant decreases in DNA were seen in both embryo and VYS after $\mathrm{CH}_{3} \mathrm{OH}$ concentrations reached $12 \mathrm{mg} / \mathrm{ml}$.

\section{Formaldehyde: Direct Addition to the Culture Medium}

$\mathrm{HCHO}$, the primary Phase I metabolite of $\mathrm{CH}_{3} \mathrm{OH}$, generated through the activity of $\mathrm{ADH1}$, caused dose-dependent loss of viability in the mouse at much lower concentrations than the parent compound. Loss of viability due to direct addition of $\mathrm{HCHO}$ to the culture medium was significant at doses of $0.004 \mathrm{mg} / \mathrm{ml}$, with a complete loss of viability produced at $0.006 \mathrm{mg} / \mathrm{ml}$ (Table 2). The incidence of incomplete axial rotation was significantly increased at $0.003 \mathrm{mg} / \mathrm{ml}$ and increase in the incidence of open neural tubes was significant at doses as low as $0.001 \mathrm{mg} / \mathrm{ml}$. Embryonic protein and DNA concentrations were decreased at $0.003 \mathrm{mg} / \mathrm{ml}$. In the VYS, protein was decreased at $0.004 \mathrm{mg} / \mathrm{ml}$ and significant reductions in DNA were observed at doses as low as $0.001 \mathrm{mg} / \mathrm{ml}$.

In the rat, significant losses of viability were seen at 0.006 $\mathrm{mg} / \mathrm{ml}$. Incomplete axial rotation was present in embryos receiving $0.003 \mathrm{mg} / \mathrm{ml}$, similar to effects produced in the mouse, but there was no increased incidence of open neural tubes at any nonlethal dose. Embryonic and VYS protein were significantly reduced beginning at $0.004 \mathrm{mg} / \mathrm{ml}$, while reductions in embryonic and VYS DNA occurred at $0.003 \mathrm{mg} / \mathrm{ml}$. 

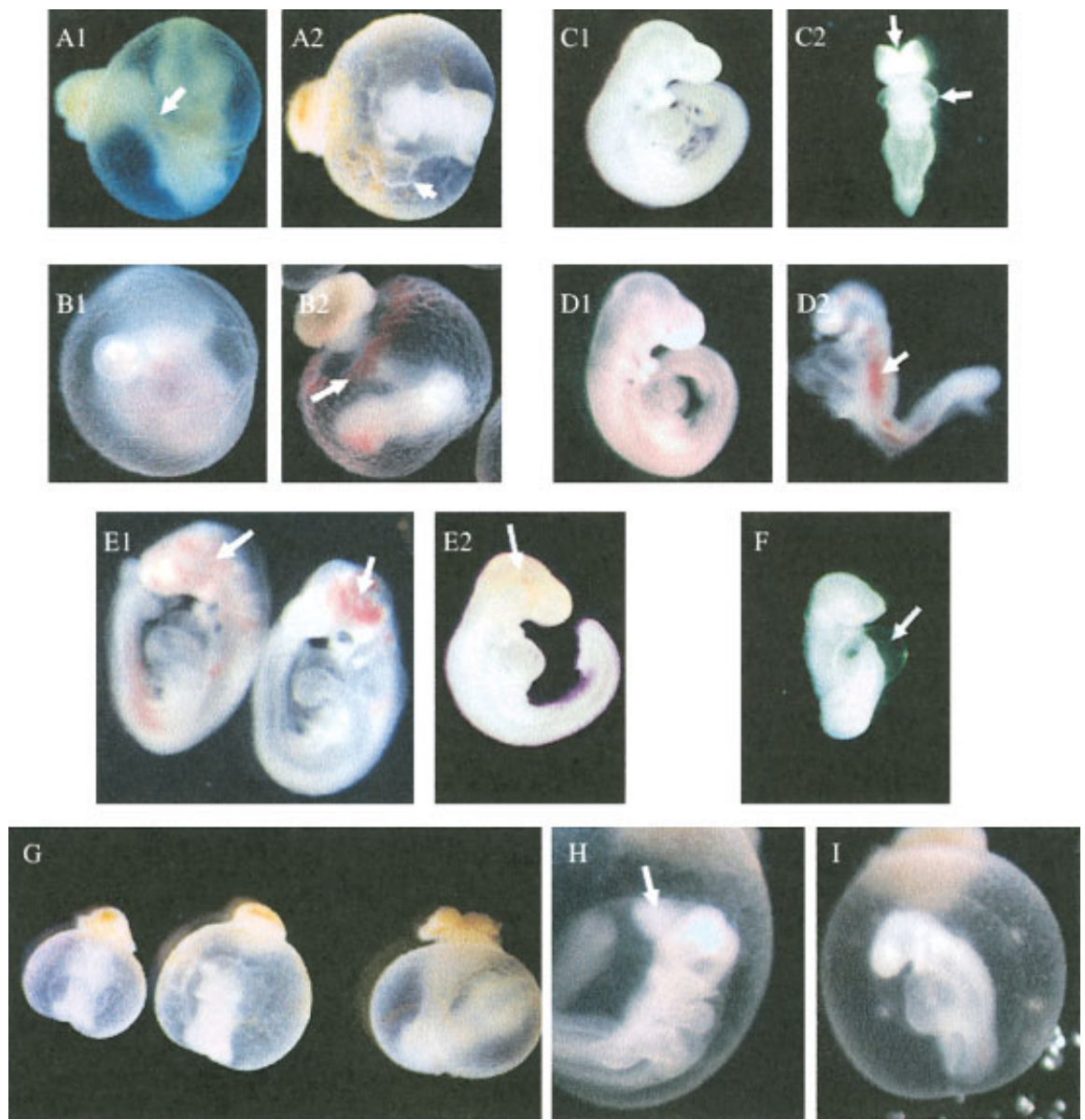

Figure 2. Characteristic dysmorphogenesis produced by $\mathrm{CH}_{3} \mathrm{OH}$ and its primary metabolites $\mathrm{HCHO}$ and $\mathrm{HCOONa}$ in rat and mouse conceptuses at a comparable stage of development (rat GD 11 and mouse GD 9). A1: Control GD 9 mouse conceptus with normal vitelline vascular development and active blood circulation in the VYS. A2: GD9 mouse conceptus following treatment with $1.0 \mathrm{mg} / \mathrm{ml} \mathrm{HCOONa}$ showing clear fluid-filled blisters in the VYS and excessive blood pooling near the ectoplacental cone (EPC). B1: Control GD 11 rat conceptus with normal vitelline vascular development and active blood circulation in the VYS. B2: Conceptuses exposed to $12 \mathrm{mg} / \mathrm{ml} \mathrm{methanol}$ showing disrupted vitelline vasculature and excessive blood pooling near the EPC. C1: Control GD 9 mouse embryo with extraembryonic membranes removed, showing normal axial rotation and morphology. C2: GD 9 mouse embryo after exposure to $10 \mathrm{mg} / \mathrm{ml} \mathrm{CH} \mathrm{OH}_{3}$ for $26 \mathrm{hr}$. Embryo has failed to complete axial rotation, anterior neural tube has failed to close, and pericardium is enlarged and filled with clear fluid. D1: Control GD 11 rat embryo with extraembryonic membranes removed. D2: GD 11 rat embryo following treatment with $12 \mathrm{mg} / \mathrm{ml}$ $\mathrm{CH}_{3} \mathrm{OH}$ for $26 \mathrm{hr}$ showing failure to complete axial rotation, microprosencephalic, abnormal blood pooling along lateral body walls, and

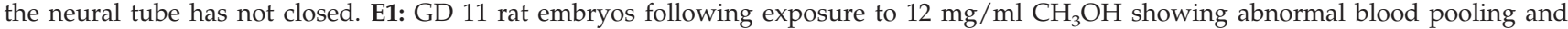
hemorrhage in the head region, behind the optic cup, and extending over the mesencephalon toward the otic vesicle. E2: GD 9 mouse embryo following exposure to $0.003 \mathrm{mg} / \mathrm{ml} \mathrm{HCHO}$. Extensive blood pooling in the head region similar to that seen for $\mathrm{CH}_{3} \mathrm{OH}$ in $\mathrm{E} 1$. $\mathrm{F}$ : GD 9 mouse embryo treated with $1 \mathrm{mg} / \mathrm{ml}$ HCOONa showing a large, clear fluid-filled pericardial sac. G: GD 9 mouse conceptuses treated

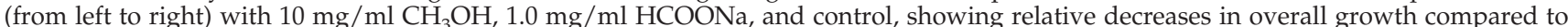
the control at right. Conceptuses have failed to complete axial rotation, show excessive blood pooling, and have necrotic debris in the amniotic space. $\mathrm{H}$ : GD 11 rat conceptus treated with $12 \mathrm{mg} / \mathrm{ml} \mathrm{CH}_{3} \mathrm{OH}$ with the neural tube open at the fore- and midbrain regions, and showing a mass of necrotic debris within the amnion. I: GD 11 rat conceptus following treatment with $12 \mathrm{mg} / \mathrm{ml} \mathrm{CH}_{3} \mathrm{OH}$ showing hypoplasia of the prosencephalon, microphthalmia, and poor vascularization in the VYS.

\section{Sodium Formate: Direct Addition to the Culture Medium}

The embryotoxicity of formic acid, the primary Phase II metabolite of $\mathrm{CH}_{3} \mathrm{OH}$ via $\mathrm{HCHO}$, was evaluated by direct addition of HCOONa directly to the culture medium. No consistent significant reductions in viability were seen in the mouse at doses up to $8 \mathrm{mg} / \mathrm{ml}$ (data not shown). Concentrations ranging from 0.5 to $4.0 \mathrm{mg} / \mathrm{ml}$ did not elicit consistent reductions in viability but did produce signifi- cant increases in incomplete axial rotation, at $0.5,2$, and 4 $\mathrm{mg} / \mathrm{ml}$. Data from the $1 \mathrm{mg} / \mathrm{ml}$ dose were inconsistent with the other data, showing no significant changes in normal rotation. Neural tube closure was affected to a small degree in a few litters, but produced no consistent change in this parameter overall. Embryonic and VYS protein were significantly reduced at doses of $4 \mathrm{mg} / \mathrm{ml}$. Although HCOONa exposure did not affect embryonic DNA, significant reductions were seen in the VYS with HCOONa 
added to the culture medium at concentrations as low as $0.5 \mathrm{mg} / \mathrm{ml}$.

In the rat, significant dose-dependent reductions in viability were seen beginning at $2 \mathrm{mg} / \mathrm{ml}$, marking the only instance in this study at which rat conceptuses were more sensitive to administered test agent than the mouse. In spite of the significant loss of viability, and with the exception of a slight increase in incomplete axial rotation at 4 $\mathrm{mg} / \mathrm{ml}$, no other morphological or growth endpoints were affected following HCOONa exposure.

In addition to the assessment of toxicity caused through direct addition of test agents to the culture medium, $\mathrm{CH}_{3} \mathrm{OH}$ and its primary metabolites were also evaluated following microinjection of chemical directly into the amniotic sac. The microinjection procedure allows for the assessment of direct exposure of the embryo proper to chemicals, thus bypassing the VYS and its potential protective and/or potentiating effects. It is not known whether the observed embryotoxicity elicited by $\mathrm{CH}_{3} \mathrm{OH}$ or its metabolites results from molecular target interactions within the embryo proper or whether nutritional or other physiological functions of the VYS are disrupted as the chemical traverses this barrier to produce an indirect effect leading to dysmorphogenesis or death.

Because of the different exposure paradigms, a direct comparison between embryos, which have been exposed as a result of materials added directly to the culture medium and material microinjected into the amniotic space, may not be entirely equivalent. Each glass pipette used for microinjection was individually calibrated for volume/ pulse prior to use, so that the amount delivered into each amnion was known. Because of the variability in micropipette tip fracture dimensions, the actual amount of material delivered from a given pulse duration varied from pipette to pipette. To provide the most realistic comparison, based on this variability, the actual delivered doses are listed as ranges of total amounts injected (in $\mu \mathrm{g}$ ), grouped according to how much was actually administered. To further facilitate comparisons, approximate concentrations within the amniotic cavity were calculated based on an average amniotic cavity volume plus the volume microinjected. Tables 1-3 show the actual amounts of chemical microinjected $(\mu \mathrm{g})$. The calculated concentrations are based on a $20-\mu l$ total estimated amniotic cavity volume, which can vary between litters and across species. Conversions to concentration using these estimates can be found in Table 4.

\section{Microinjection of $\mathrm{CH}_{3} \mathrm{OH}$}

Mouse conceptuses microinjected with $\mathrm{CH}_{3} \mathrm{OH}$ exhibited loss of viability within the $46-89 \mu \mathrm{g}$ estimated concentration range, indicating that immediate exposure to the embryo produced viability effects at slightly lower concentrations than when added to the culture medium. Rat conceptuses also responded within the 46-89 $\mu \mathrm{g}$ range with significant loss of viability, indicating that the differential sensitivity seen when test agents were added directly to the culture medium was no longer evident. This could be used as evidence that metabolic or physiological activities within the VYS may be at least partly responsible for the differences in sensitivity.

In terms of malformation endpoints, the rat showed an increased incidence of incomplete axial rotation but rotation defects were less severe (partial rotation in most em-
Table 4

Estimated Concentrations of Test Agents Microinjected Into the Amniotic Compartment

\begin{tabular}{lcc}
\hline Chemical & $\begin{array}{c}\text { Microinjected } \\
(\mu \mathrm{g})\end{array}$ & $\begin{array}{c}\text { Microinjected concentration } \\
\text { a } \\
(\mathrm{mg} / \mathrm{ml})\end{array}$ \\
\hline $\begin{array}{c}\text { Methanol } \\
\left(\mathrm{CH}_{3} \mathrm{OH}\right)\end{array}$ & $1-45$ & $0.1-2.3$ \\
& $46-89$ & $2.3-4.5$ \\
& $90-134$ & $4.5-6.7$ \\
& $135-178$ & $6.7-9.0$ \\
Formaldehyde & & \\
$\quad(\mathrm{HCHO})$ & $0.003-0.5$ & $0.0001-0.0002$ \\
& $0.501-1.0$ & $0.0002-0.05$ \\
& $1.01-1.5$ & $0.05-0.075$ \\
& $1.51-2.0$ & $0.075-0.10$ \\
Sodium formate & & \\
$\quad(\mathrm{HCOONa})$ & $0.03-0.5$ & $0.002-0.025$ \\
& $0.51-1.0$ & $0.025-0.05$ \\
& $1.01-1.5$ & $0.05-0.075$ \\
& $1.51-4.0$ & $0.075-0.20$ \\
\hline
\end{tabular}

${ }^{a}$ Estimated concentrations based on an average amniotic fluid volume of $20 \mu \mathrm{l}$ after microinjection.

bryos) overall than those seen when $\mathrm{CH}_{3} \mathrm{OH}$ was added directly to the culture medium. No open neural tubes were seen at any microinjected dose in the rat. Mouse conceptuses microinjected with $\mathrm{CH}_{3} \mathrm{OH}$ showed significant increases in incomplete axial rotation and neural tube closure in the lowest 1-45 $\mu \mathrm{g}$ dose range tested. These defects were accompanied by some significant decreases in embryonic and VYS protein and DNA that were not seen in the rat (Table 1$)$

\section{Microinjection of Formaldehyde}

When microinjected into the mouse amniotic space, $\mathrm{HCHO}$ produced decreases in viability in the lowest dose range of $0.003-0.5 \mu \mathrm{g}$. This range falls below the concentrations of $\mathrm{HCHO}$ that were required to produce loss of viability when added to the culture medium. Significant increases in incomplete axial rotation and neural tube closure, as well as decreased VYS DNA, were also seen at this concentration range. At higher dose ranges, significant decreases in embryonic protein, VYS protein, and embryonic and VYS DNA were also observed. In contrast, the rat embryo exhibited significant decreases in normal axial rotation at the 1.01-1.5 $\mu \mathrm{g}$ range, but showed no other malformation or growth effects including the complete preservation of embryonic and VYS protein and DNA levels. These data imply that $\mathrm{HCHO}$ is directly toxic to the mouse and that the level of protection afforded by chemical transit through the VYS in this species may be insignificant (i.e. the concentrations at which viability is lost and malformations elicited do not differ a great deal whether $\mathrm{HCHO}$ is added to the culture medium or microinjected into the amniotic space). On the other hand, the rat requires a 10-15-fold higher concentration to elicit the same decrease in viability and increase in incomplete axial rotation. This implies that the VYS may be involved in bioactivation of $\mathrm{CH}_{3} \mathrm{OH}$ or may otherwise be particularly sensitive to $\mathrm{HCHO}$, leading to indirect effects due to altered VYS function. 


\section{Microinjection of Sodium Formate}

Microinjection of HCOONa into the amniotic space resulted in decreased viability and increased incidence of incomplete axial rotation in both mice and rats at concentrations that were less than those required to cause the same incidence of effect when the compound was added to the culture medium. This result implies a possible protective role for the VYS in HCOONa embryotoxicity. Significant loss of viability was seen at the 1.01-1.5 $\mu \mathrm{g}$ range for the mouse and in the 1.51-4.0 $\mu \mathrm{g}$ range in the rat. Incomplete axial rotation was observed at the lowest concentration range $(0.03-0.5 \mu \mathrm{g})$ in the mouse and at the $0.51-1.0 \mu \mathrm{g}$ range in the rat. Significant increases in the incidence of incomplete neural tube closure were observed at the 1.01$1.5 \mu \mathrm{g}$ range for both species. No significant variation in embryonic or VYS protein was observed in the mouse at any of the dose ranges used, although significant reductions in VYS DNA were observed beginning at the lowest dose range tested. In the rat, significant reductions in embryonic and VYS protein were first observed at the 0.51-1.0 $\mu \mathrm{g}$ range. Embryonic and VYS DNA were also significantly reduced beginning at the same dose range.

\section{DISCUSSION}

Methanol $\left(\mathrm{CH}_{3} \mathrm{OH}\right)$ has been shown to elicit dose-dependent toxicity in organogenesis-stage rat and mouse conceptuses following exposure in rodent whole embryo culture. Mouse embryos are more sensitive than rats based on molar equivalent doses, requiring twice the dose to elicit similar toxic effects, similar to what has been reported for whole animal studies (Nelson et al., 1985; Andrews et al., 1993; Rogers et al., 1993; Rogers and Mole, 1997). The two common direct metabolites of $\mathrm{CH}_{3} \mathrm{OH}$, namely $\mathrm{HCHO}$ and HCOONa, are also toxic in a dose-dependent manner when added directly to the culture medium. Previous studies showing $\mathrm{CH}_{3} \mathrm{OH}$ metabolism and toxicity to be sensitive to changes in intracellular GSH status imply that $\mathrm{HCHO}$, generated in the first step of $\mathrm{CH}_{3} \mathrm{OH}$ metabolism, could be an important contributor to overall toxicity. We report here that addition of this very reactive aldehyde causes toxicity at concentrations nearly 1000-fold lower than either $\mathrm{CH}_{3} \mathrm{OH}$ or $\mathrm{HCOONa}$, further suggesting that relatively small amounts of $\mathrm{HCHO}$ generated as a result of conceptual biotransformation within target cells could contribute significantly to embryotoxicity and mortality.

With regard to mechanisms of toxicity, it was also important to determine whether the direct toxicity of $\mathrm{CH}_{3} \mathrm{OH}$ or its metabolites was responsible for observed effects or whether extraembryonic organs such as the VYS could also be playing a potentiating or protective role. To assess this possibility, we attempted to bypass VYS function by microinjecting chemicals directly into the amniotic sac. While this method does not allow for absolute calculation of amniotic concentration (the inability to determine the exact amniotic volume for every conceptus), it does serve as a good comparative index of toxicity and provides a means to assess potential contributions of the VYS. Calculations of amniotic sac volume based on distribution of ${ }^{14} \mathrm{C}$-glucose and FITC-albumin suggest that amniotic fluid volumes range from 15 to $20 \mu \mathrm{l}$ at the developmental stages that are optimal for whole embryo culture in rats (GD 10) and mice (GD 9). Calculations for concentrations shown in Table 4 were based on mean estimated amniotic cavity volumes from each species, which could be somewhat variable. Ranges of doses are used in describing the microinjection data to reflect the range of actual amounts delivered by individual calibrated micropipettes. Normalized to a $20-\mu 1$ total amniotic fluid volume, the reported ranges of injected concentrations for $\mathrm{CH}_{3} \mathrm{OH}$ closely parallel those used for direct addition to the culture media.

Comparisons of toxicities produced by chemicals added to the culture medium to the same agents microinjected show that the VYS may have differential effects on the various endpoints measured. Rat and mouse conceptuses were both more sensitive to the effects of microinjected $\mathrm{CH}_{3} \mathrm{OH}$ when compared on a general concentration $(\mathrm{mg} /$ $\mathrm{ml}$ ) basis, suggesting that the VYS may provide a protective function in the metabolism and removal of $\mathrm{CH}_{3} \mathrm{OH}$ or its toxic metabolites. Likewise, mouse embryos were much more sensitive to the toxicity of microinjected $\mathrm{HCHO}$, indicating an attenuated capacity to detoxify this reactive aldehyde. In contrast, the microinjection of $\mathrm{HCHO}$ into the rat amnion produced significant reductions in viability and increased incidence of abnormal axial rotation at relative concentrations that were approximately 10-fold higher than those required to produce the same effects when added to the culture medium. This result suggests that the intrinsic capacity of the rat embryo to protect itself is greater than that seen in the mouse. Because of the high reactivity of $\mathrm{HCHO}$ in biological tissues, free $\mathrm{HCHO}$ would not be expected to move easily from cell to cell and would likely interact with molecular targets at the site of first contact or the site of intracellular formation by biotransformation enzymes. Several factors may contribute to this species difference, including antioxidant content, such as GSH, as well as the specific activity of biotransformation enzymes responsible for converting $\mathrm{HCHO}$ to less toxic metabolites. Mouse VYSs (GD 9.5) contain approximately $16 \mathrm{pmol} \mathrm{GSH} / \mu \mathrm{g}$ protein (Harris et al., 1995). Comparatively, the rat VYS of similar developmental age (GD 11) has approximately 65\% more GSH, measuring nearly 25 pmol GSH/ $\mu$ g protein (Ozolins and Hales, 1999). Visceral yolk sac antioxidant differences may account for mouse sensitivity and rat resistance to $\mathrm{CH}_{3} \mathrm{OH}$, but do not fully address the sensitivity and resistance of the embryo proper of each respective species to direct $\mathrm{CH}_{3} \mathrm{OH}$ and $\mathrm{CH}_{3} \mathrm{OH}$ metabolite exposure. While antioxidants like GSH are of importance in the protective function of the VYS, they may also play a crucial role in protection of the early-organogenesis embryo. Mouse embryonic GSH concentrations are approximately $11 \mathrm{pmol} \mathrm{GSH} / \mu \mathrm{g}$ protein (Harris et al., 1995), but the rat embryo contains significantly more GSH, approximately $18 \mathrm{pmol} \mathrm{GSH} / \mu \mathrm{g}$ protein (Harris, 1993).

Previous studies of enzymatic activity (Harris et al., 2003) suggest that the rat should be capable of generating greater amounts of $\mathrm{HCHO}$ in the VYS due to significantly higher specific activities for ADH1. Embryonic activities for this enzyme are very similar in rats and mice except for early somite stages, in which the mouse activity is significantly lower. Detoxification of $\mathrm{HCHO}$ through the nicotinamide adenine dinucleotide reduced form (NADH) and GSH-dependent ADH3 pathway, however, clearly favors the rat. Specific activities for ADH3 are significantly higher in the rat VYS, compared to mouse, throughout the culture period. In the embryo, differences are even more pronounced; mouse ADH3-specific activities remain significantly low until reaching the 14-16 somite range. Higher 
activities of $\mathrm{ADH} 3$ and more abundant GSH in the rat embryo suggest that this species may be intrinsically more capable of protection against the toxicity of $\mathrm{HCHO}$, whether generated intracellularly from $\mathrm{CH}_{3} \mathrm{OH}$ or as a result of direct exposure to the agent.

No agent-specific lesions from $\mathrm{CH}_{3} \mathrm{OH}$ or either of its metabolites were observed, although the incidence and severity of dysmorphogenesis and growth parameters varied widely by compound. The more resistant rat was much less sensitive to the production of neural tube defects, consistent with in vivo studies (Nelson et al., 1985; Andrews et al., 1993; Rogers et al., 1993; Rogers and Mole, 1997). In fact, only $\mathrm{CH}_{3} \mathrm{OH}$ added to the culture medium produced an increased incidence of open neural tubes in the rat. Our assertion that $\mathrm{HCHO}$ may be the ultimate toxicant from $\mathrm{CH}_{3} \mathrm{OH}$ exposure, based on dose-response and metabolism data, may be supported by the evidence that the rat may efficiently remove $\mathrm{HCHO}$ and that the species shows a lower incidence of abnormal neural tube closure. We have hypothesized in the past that incomplete axial rotation may be mediated by effects in the VYS and may, therefore, occur independent of direct embryonic toxicity. Consistent with exposure to $\mathrm{CH}_{3} \mathrm{OH}$, and subsequent generation of $\mathrm{HCHO}$ as the ultimate toxicant, is the observation that both compounds are capable of producing the vascular defects in which large blood pools are observed in the embryonic head and in the VYS, sometimes accompanied by hemorrhage. Other embryotoxic compounds, such as the pesticide aminocarb, produce an identical lesion in rodent whole embryo culture and are also known to produce $\mathrm{HCHO}$ as the principal and most abundant metabolite (Berberian and Harris, 1997). Distension of the anterior cardinal vein and abnormal pooling of blood has also been attributed to localized hypoxia that could result from excessive biotransformation activity or enhanced local oxygen consumption (Grabowski, 1970).

These results suggest that enhanced bioactivation or altered conceptual functions in the rat VYS may be contributing to $\mathrm{CH}_{3} \mathrm{OH}$ toxicity and that this pattern does not occur in the mouse. In the results reported here, virtually every incidence of decreased neural tube closure is accompanied by a significant specific reduction in embryonic protein. This was true for all three of the chemicals tested. Bypass of the VYS, especially in the rat, resulted in significant preservation of embryonic protein when $\mathrm{CH}_{3} \mathrm{OH}$ and $\mathrm{HCHO}$ were administered, but not when the terminal metabolite HCOONa was given. Significant increases in abnormal axial rotation are often accompanied by significant reductions in VYS, but not embryonic DNA. The mechanistic significance of this is not known. Using both protein and DNA content as measures of growth retardation, $\mathrm{CH}_{3} \mathrm{OH}$ microinjection only affected the mouse, where both protein and DNA content were significantly decreased with $4.5-6.7 \mathrm{mg} / \mathrm{ml}$ treatments. $\mathrm{HCHO}$ treatments showed significant growth retardation (protein and DNA) in both the rat and mouse embryo with dosages as low as $0.05 \mathrm{mg} / \mathrm{ml}$. Sodium formate did not retard the growth of rat or mouse embryos based on crown rump length, protein content, and DNA content, except for some isolated cases at 2 and $4 \mathrm{mg} / \mathrm{ml}$, even though significant increases in lethality and abnormal axial rotation were evident. The mouse VYS was selectively sensitive to HCOONa exposure. These results suggest that while $\mathrm{HCHO}$ may be the metabolite most responsible for embryonic death, $\mathrm{CH}_{3} \mathrm{OH}$ and $\mathrm{HCHO}$, may contribute most significantly to growth retardation and possible terata, in both species. It is difficult to determine definite factors that account for $\mathrm{CH}_{3} \mathrm{OH}$ sensitivity, but as previously mentioned, the VYS, which envelops both the rat and mouse embryo, may serve as a protective barrier against toxicants like $\mathrm{CH}_{3} \mathrm{OH}$ (Harris, 1993).

Based on the small amounts of $\mathrm{HCHO}$ necessary to produce lesions in this study, we speculate that $\mathrm{HCHO}$ is a likely ultimate embryotoxicant. Intracellular metabolism of $\mathrm{CH}_{3} \mathrm{OH}$ to $\mathrm{HCHO}$ within target cells of the embryo and VYS may be sufficient for causing the loss of viability and dysmorphogenesis observed. HCHO is very reactive and can undergo adduct, alkylation, and condensation (methane bridge formation) reactions with proteins, amino acids, nucleic acids, and nucleosides (French and Edsall, 1945; Auerbach et al., 1977). Injection of ${ }^{14} \mathrm{C}$-labeled $\mathrm{HCHO}$ into mice on GD 16 showed increased, preferential accumulation of $\mathrm{HCHO}$ in the placenta, uterus, and fetal tissues as compared to other maternal organs. Furthermore, elimination of radiolabeled $\mathrm{HCHO}$ was significantly slower in fetal tissues than in maternal tissues (Thrasher and Kilburn, 2001), suggesting that the developing embryo is a target tissue. In the maternal liver, protection from $\mathrm{HCHO}$ toxicity relies on GSH and the ultimate formation of Sformylglutathione (Marks et al, 1981; Farooqui et al., 1986).

While these studies have produced promising and interesting results, their extrapolation to human $\mathrm{CH}_{3} \mathrm{OH}$ exposure may not correlate well. Results in this study, as well as others, suggest the importance of VYS as a protective barrier during development (Harris, 1993; Choe et al., 2001; Hansen et al., 2001; Ozolins and Hales, 1999). However, most data suggest that human embryonic development does not have the same VYS protective effects. The rodent VYS envelops the embryo throughout gestation, while the VYS only partially surrounds the embryo for a short developmental period in human embryos. Most studies do not assess the effect of $\mathrm{CH}_{3} \mathrm{OH}$ directly on the embryo. It would be most likely that human embryo exposures occur as a result of a direct interaction with the embryo and not secondarily following detoxification and metabolism by the VYS.

These microinjection studies demonstrate the importance of the VYS in rodent conceptuses and suggest that they play a crucial role in the protection from toxicants like $\mathrm{CH}_{3} \mathrm{OH}$. These observations also suggest that the mouse embryo is much more susceptible to $\mathrm{CH}_{3} \mathrm{OH}$ and related metabolites than the rat embryo, in which embryolethal doses of $\mathrm{CH}_{3} \mathrm{OH}, \mathrm{HCHO}$, and $\mathrm{HCOONa}$ were more prevalent at lower concentrations, and that $\mathrm{HCHO}$ may be the most likely ultimate toxicant. Clearly, further work is needed to evaluate mechanisms of methanol toxicity and the protective role of the VYS, including species-specific antioxidant and detoxification differences between the rat and mouse.

\section{REFERENCES}

Abbott BD, Ebron-McCoy M, Andrews JE. 1995. Cell death in rat and mouse embryos exposed to methanol in whole embryo culture. Toxicology 97:159-171.

Andrews JE, Ebron-McCoy M, Logsdon TR, et al. 1993. Developmenta toxicity of methanol in whole embryo culture: a comparative study with mouse and rat embryos. Toxicology 81:205-215.

Andrews JE, Ebron-McCoy M, Kavlock RJ, Rogers JM. 1995. Developmental toxicity of formate and formic acid in whole embryo culture: a comparative study with mouse and rat embryos. Teratology 51:243-251.

Andrews JE, Ebron-Mccoy M, Schmid JE, Svendsgaard D. 1998. Effects of 
combinations of methanol and formic acid on rat embryos in culture. Teratology 58:54-61.

Auerbach C, Moustchem-Dahmen M, Moustschen J. 1977. Genetic and cytogenetic effects of formaldehyde and related compounds. Mutat Res 39:317-362.

Berberian RM, Harris C. 1997. In vitro embryotoxicity of the pesticide aminocarb in organogenesis-stage rat conceptuses. Toxicology 36:100.

Bolon B, Welsch F, Morgan KT. 1994. Methanol-induced neural tube defects in mice: pathogenesis during neurulation. Teratology 49:497-517.

Bradford MM. 1976. A rapid and exposed to methanol in whole embryo culture. Sensitive method for the quantitation of microgram quantities of protein utilizing the principle of protein-dye binding. Anal Biochem $72: 248-254$.

Burbacher T, Shen D, Grant K, et al. 1999. Reproductive and offspring developmental effects following maternal inhalation exposure to methanol in nonhuman primates. Res Rep Health Eff Inst 89:i-ii, 1-117 [Discussion 119-133].

Cederbaum AI, Qureshi A. 1982. Role of catalase and hydroxyl radicals in the oxidation of methanol by rat liver microsomes. Biochem Pharmaco 31:329-335.

Choe H, Hansen JM, Harris C. 2001. Spatial and temporal ontogenies of glutathione peroxidase and glutathione disulfide reductase during development of the prenatal rat. J Biochem Mol Toxicol 15:197-206.

Clary JJ. 2003. Methanol, is it a developmental risk to humans? Regul Toxicol Pharmacol 37:83-91.

Davis LE, Hudson A, Benson BE, et al. 2002. Methanol poisoning exposures in the United States: 1993-1998. J Toxicol Clin Toxicol 40:499-505.

Dawidek-Pietryka K, Szczepaniak S, Dudka J, Mazur M. 1998. In vitro studies of human alcohol dehydrogenase inhibition in the process of methanol and ethylene glycol oxidation. Arch Toxicol 72:604-607.

Fantel AG, Greenaway JC, Juchau MR, Shepard TH. 1979. Teratogenic bioactivation of cyclophosphamide in vitro. Life Sci 25:67-72.

Farooqui MY, Upreti RK, Ahmed AE, Ansari GA. 1986. Influence of intraperitoneally administered formaldehyde on bile production and tissue glutathione levels in rats. Res Commun Chem Pathol Pharmacol 53: 233-236.

French G, Edsall JT. 1945. The reactions of formaldehyde with amino acids and proteins. Adv Protein Chem 2:277-325.

Grabowski CT. 1970. Embryonic oxygen deficiency-a physiological approach to analysis of teratological mechanisms. In: Woollam DHM, editor. Advances in teratology. Vol 4. New York: Academic Press. p. 125-169.

Hansen JM, Choe HS, Carney EW, Harris C. 2001. Differential antioxidant enzyme activities and glutathione content between rat and rabbit conceptuses. Free Radic Biol Med 30:1078-1088.
Harris C, Namkung MJ, Juchau MR. 1987. Regulation of intracellular glutathione in rat embryos and visceral yolk sacs and its effect on 2-nitrosofluorene-induced malformations in the whole embryo culture system. Toxicol Appl Pharmacol 88:141-52.

Harris C. 1993. Glutathione biosynthesis in the postimplantation rat conceptus in vitro. Toxicol Appl Pharmacol 120:247-256.

Harris C, Wang S-W, Lauchu JJ, Hansen JM. 2003. Methanol metabolism and embryotoxicity in rat and mouse conceptuses: comparisons of alcohol dehydrogenase (ADH1), formaldehyde dehydrogenase (ADH3), and catalase. Reprod Toxicol 17:349-357.

Harris C, Dixon M, Hansen JM. 2004. Glutathione modulates methanol, formaldehyde, and formate toxicity in cultured rat conceptuses. Cell Biol Toxicol 20:133-145.

Labarca C, Paigen K. 1980. A simple, rapid, and sensitive DNA assay procedure. Anal Biochem 102:344-352.

Lanigan S. 2001. Final report on the safety assessment of methyl alcohol. Int J Toxicol 20(Suppl 1):57-85

Ma TH, Harris MM. 1988. Review of the genotoxicity of formaldehyde. Mutat Res 196:37-59.

Marks TA, Worthy WC, Staples RE. 1981. Influence of formaldehyde and Sonacide $^{\mathrm{TM}}$ (potentiated acid glutaraldehyde) on embryo and fetal development in mice. Teratology 22:21-28.

Nelson BK, Brightwell WS, MacKenzie OR, et al. 1985. Teratological assessment of methanol and ethanol at high inhalation levels in rats. Fundam Appl Toxicol 5:727-736

Ozolins TR, Hales BF. 1999. Tissue-specific regulation of glutathione homeostasis and the activator protein-1 (AP-1) response in the rat conceptus. Biochem Pharmacol 57:1165-1175.

Rogers JM, Mole ML, Chernoff N, et al. 1993. The developmental toxicity of inhaled methanol in the CD-1 mouse, with quantitative dose-response modeling for estimation of benchmark doses. Teratology 47:175-188.

Rogers JM, Mole ML. 1997. Critical periods of sensitivity to the developmental toxicity of inhaled methanol in the CD-1 mouse. Teratology 55:364-372.

Stark KL, Harris C, Juchau MR. 1987. Embryotoxicity elicited by inhibition of gamma-glutamyltransferase by Acivicin and transferase antibodies in cultured rat embryos. Toxicol Appl Pharmacol 89:88-96.

Stark KL, Lee QP, Namkung MJ, et al. 1990. Dysmorphogenesis elicited by microinjected acetaminophen analogs and metabolites in rat embryos cultured in vitro. J Pharmacol Exp Ther 255:74-82.

Thrasher JD, Kilburn KH. 2001. Embryo toxicity and teratogenicity of formaldehyde. Arch Environ Health 56:300-311.

von Burg R. 1994. Methanol. J Appl Toxicol 14:309-313.

Zorzano A, Herrera E. 1989. Disposition of ethanol and acetaldehyde in late pregnant rats. Pediatr Res 25:102-106. 